\title{
Design, Identidade e Produção Local
}

\section{Resumo:}

O texto apresenta os paradigmas de Design e Identidade enquadrados no Território, introduzindo, num segundo momento, a ideia de Identidade Local onde são explanados os conceitos de Naturalidade Identitária, Construção Identitária e o Fazer local, bem como a relação entre Cultura, Território e Identidade, explorando ainda, neste quadro de referências, a reinvenção da identidade, a identidade como veículo da estabilidade cultural e a identidade e a sua génese imaterial.

Palavras-chave: Design, Identidade Local, Território, Fazer Local, Cultura Material

\section{Design, Identity and Local Production}

\section{Abstract}

The text presents the paradigms of Design and Identity framed in the Territory, it introduces the idea of Local Identity. It explains the concepts of Naturalness and Identity, Identity Construction, and Local Making. It also introduces the relationship between Culture, Territory, and Identity. It explores the identity reinvention and its use as a vehicle for cultural stability.

Keywords: Design, Local Identity, Territory, Local Making, Material Culture

1 Designer e Professor Associado com Agregação da Faculdade de Belas-Artes da Universidade de Lisboa. Professor visitante da Facoltà di Architettura da Sapienza Università di Roma. 
Pela primeira vez dei conta que a identidade não era uma coisa pré-fabricada mas uma criação. Os seres humanos criam a sua identidade.

Adonis (Ali Ahmad Said Esber), Público.pt, 17/08/2012.

O excerto do poeta sírio Adonis com o qual inicio este texto, sintetiza a génese do seu conteúdo.

Em primeiro lugar pela importância que assume a sua perspectiva de identidade como uma entidade em constante criação, reconstruindo-se através da incessante intervenção do Homem e em segundo lugar pela ligação que partilha com o Design, para o qual a inovação é a sua principal dinâmica, estabelecendo-se nesta dimensão criadora, uma aproximação entre Identidade e Design.

A primeira característica de uma identidade é seguramente a sua "naturalidade".

Esta naturalidade prende-se com uma localização geográfica, quer seja pela identificação de um conjunto de características atmosféricas e materiais de um local, quer seja pela determinação do nascimento e crescimento de um ser humano, de um animal ou de uma coisa.

A identidade é também uma dimensão em constante mutação e transformação, sobretudo através da manipulação da cultura, onde encontra sempre novas práticas materiais, ideológicas e rituais que dão origem a novos resultados sustentados numa naturalidade identitária.

Esta relação bilateral entre cultura e meio produz a identidade e é também o lugar que a abriga.

Constantemente reinventada e acrescentada, a identidade remete-nos sempre para uma memória dessa naturalidade mesmo que recriada através da virtualidade da concepção, como observa o sociólogo e ensaísta polaco Zygmunt Bauman: «o recurso à identidade deveria ser considerado um processo contínuo de redefinirse e de inventar e reinventar a sua própria história.» (Bauman, 2005, p. 13).

Nesta dimensão conceptual, a identidade além de constatada, pode ser reinventada e o seu conjunto material parte sempre de uma naturalidade, que se manifesta em tipologias particulares de uma dada cultura, em materiais e técnicas de produção autóctones e em rituais que identificam posturas e usos particulares.

Estas manifestações contribuem (elas mesmas) para somar identidade à identidade, acrescentando novos artefactos que conduzem e apresentam novas equações e equilíbrios desses elementos identitários. Ao somar um valor qualitativo às acções decorrentes do trabalho, Richard Sennett reflecte: «Mas a acção, sobretudo no que diz respeito ao trabalho de boa qualidade, não tem lugar no vazio social ou emocional; o desejo de fazer algo bem é um teste decisivo para a nossa identidade.» (Sennett, 2012, p. 99). 


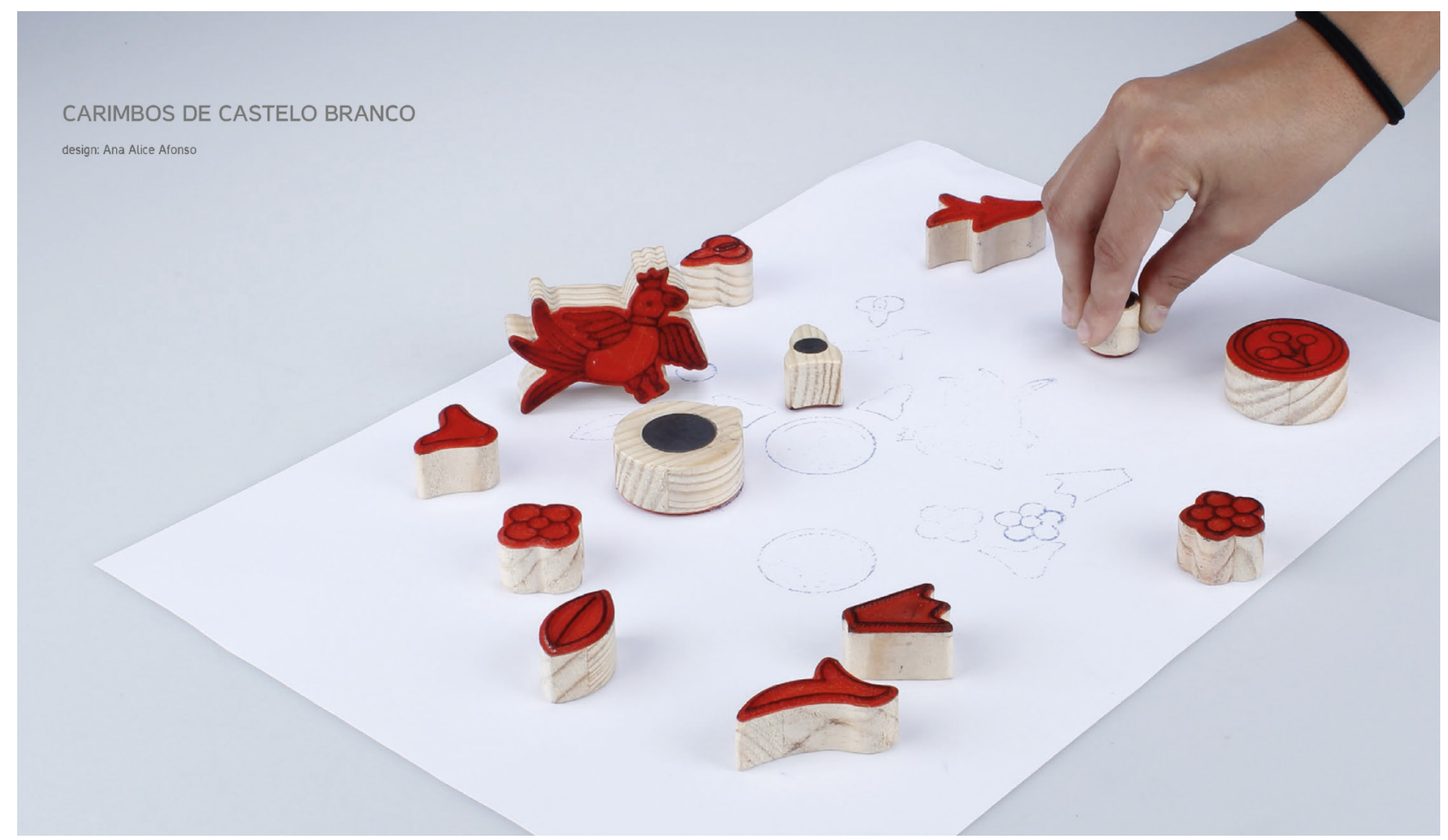

Fig. 1. Carimbos de Castelo Branco Design: Ana Alice Afonso Designesart - Novos Rituais Novas Práticas Locais

A identidade é também um garante de estabilidade cultural. Através dos diferentes suportes materiais, emergentes de uma génese identitária, transmite-se segurança e criam-se vínculos emocionais, os quais, por sua vez, atribuem maior coesão ao espaço cultural.

A capacidade de congregar aç̧ões materiais ou imateriais em torno de uma identidade local, consolida simultaneamente o domínio cultural e os indivíduos que nele participam.

Estas manifestações conservam em si um conjunto de elementos imagéticos que, ao longo dos tempos vão sendo transformados e acrescentados de acordo com uma anuência social, constituindo-se assim como um valor necessário à consolidação de uma sociedade.

As propostas afectas a uma identidade consolidam, ao longo do tempo, um colectivo identitário, acumulando um manancial de valores expressivos que despertam soluções adequadas a novos acontecimentos.

Estas concepções materiais são assim uns fieis depositários da identidade, despertando em nós a capacidade de imaginar, reconstruir e perspectivar um acontecimento do passado, do presente e até do futuro através de um artefacto envolvido num contexto específico ou centrado numa acção originária de uma localização geográfica.

É frequente, através desta propriedade dos artefactos materializarem os valores da identidade de um lugar, estabelecer comparações, analogias ou descrever o percurso de uma determinada técnica, modo de fazer e repertório visual comum a diferentes identidades distanciadas no espaço e no tempo. 


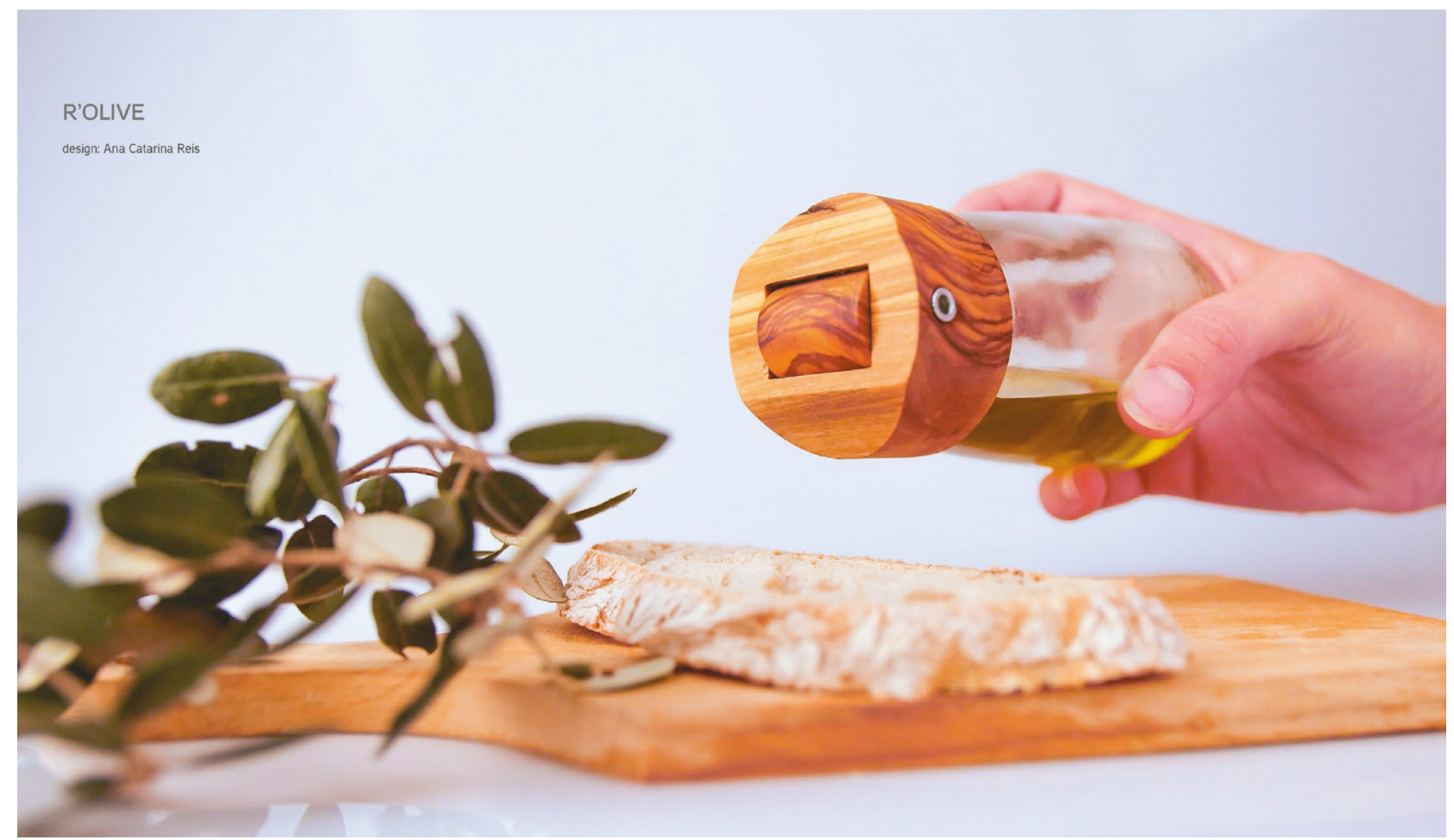

Fig. 2. R'olive Design: Ana Catarina Reis Designesart - Novos Rituais Novas Práticas Locais

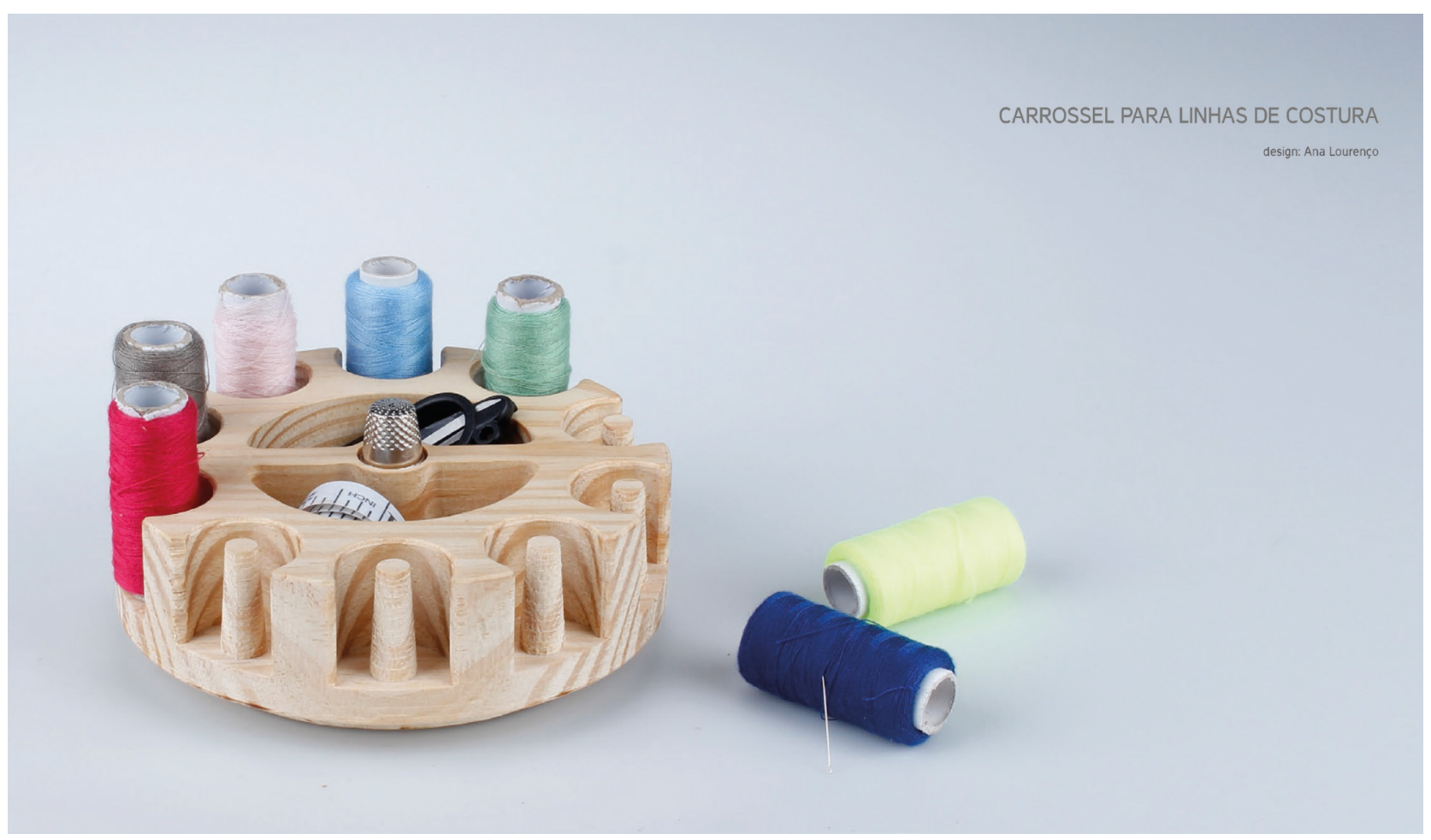

Fig. 3.

Design: Ana Lourenço Designesart - Novos Rituais Novas Práticas Locais 


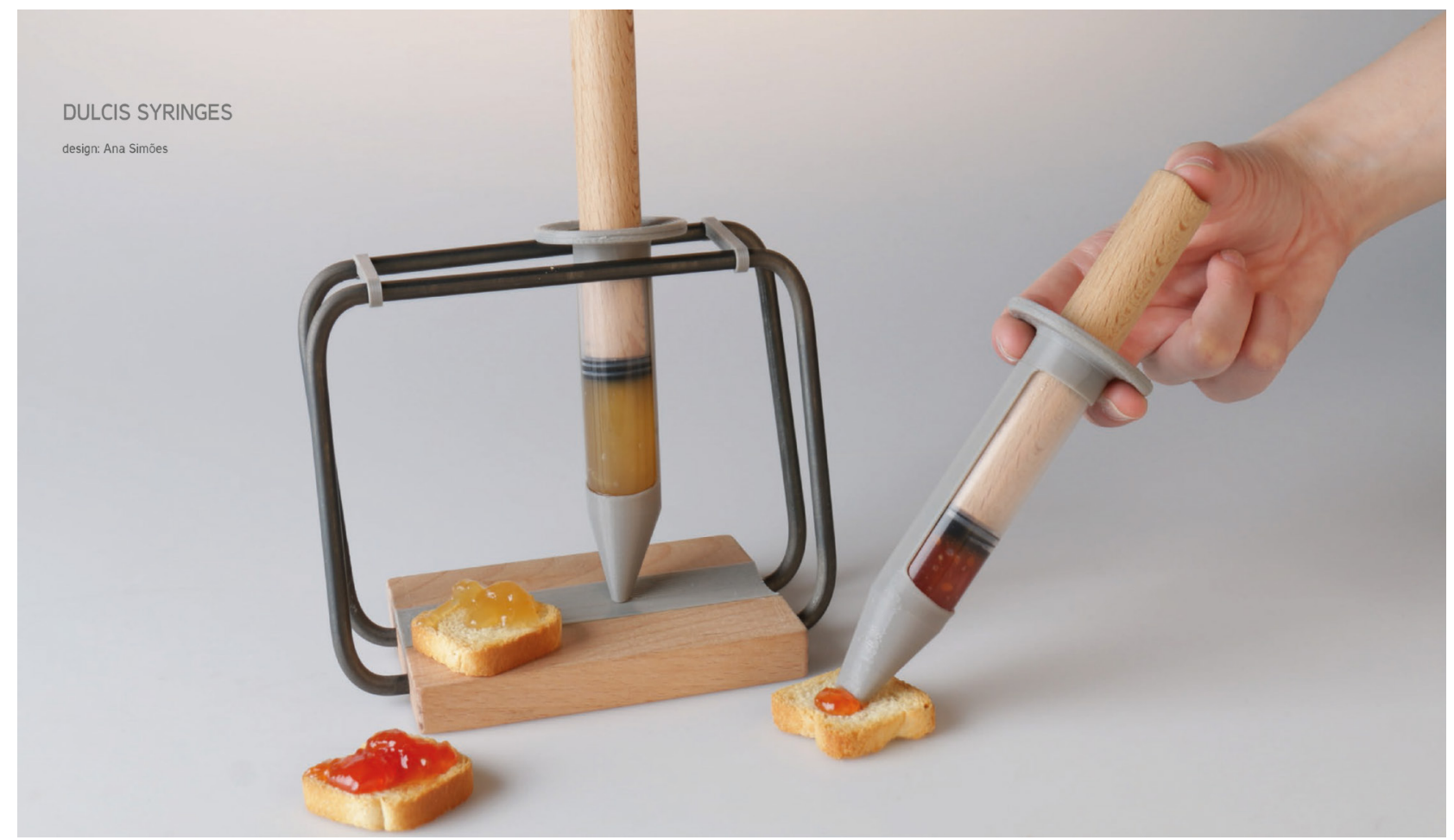

Fig. 4. Dulcis Syringes Design: Ana Simões Designesart - Novos Rituais Novas Práticas Locais

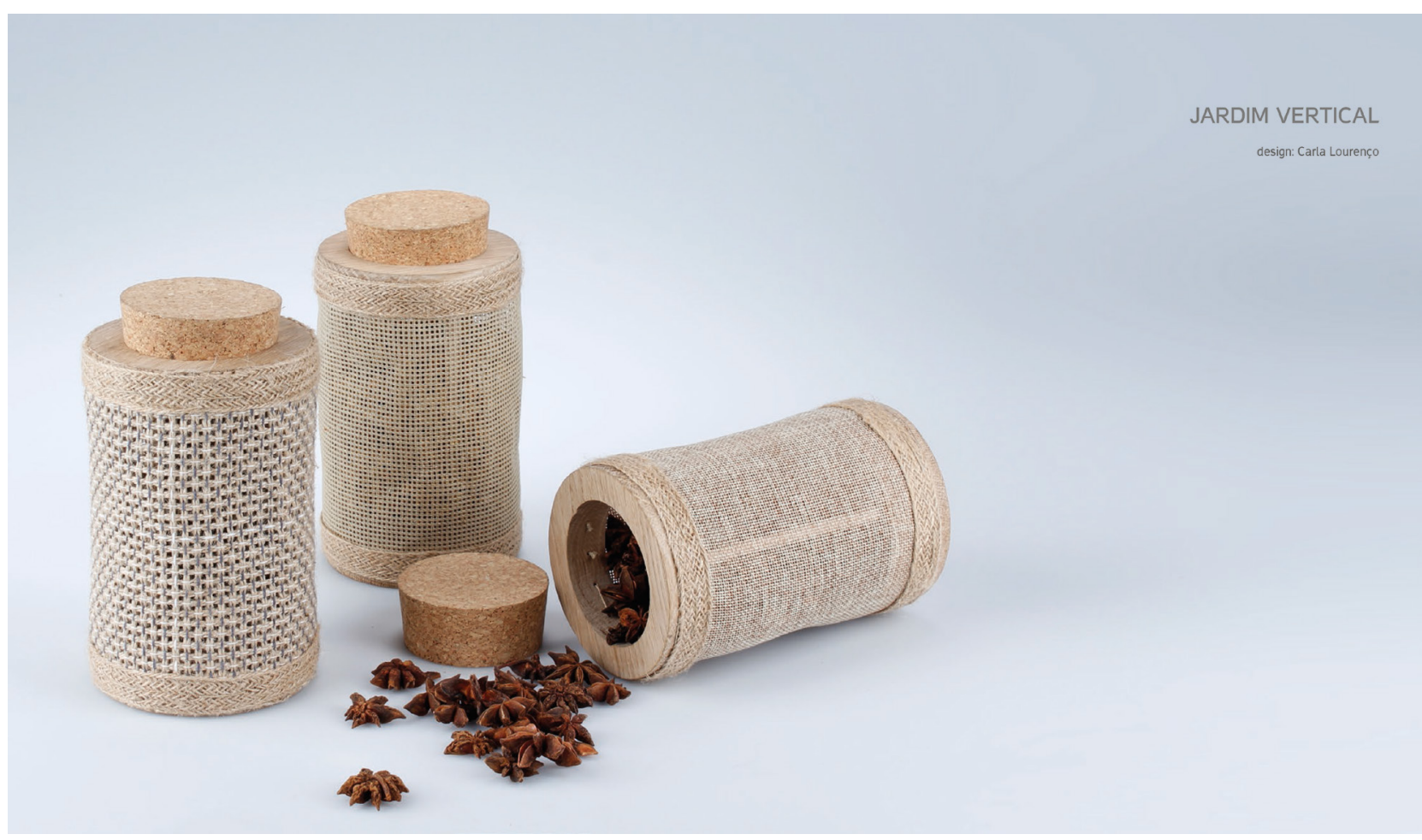

Fig. 5. Jardim Vertical

Design: Carla Lourenço Designesart - Novos Rituais Novas Práticas Locais 
Projectar, tendo como universo desta acção uma identidade local suportada por uma comunidade e por um território, constitui uma oportunidade para o projectista explorar os elementos e as práticas que caracterizam a comunidade da qual faz parte ou intervir num território que não sendo o seu, disponibiliza novas dinâmicas de projecto. Esta constatação pretende apenas enfatizar o facto de que os elementos identitários não são estanques e reservados aos indivíduos naturais dessa identidade, encontrando-se disponíveis para quem os quer conhecer e com eles trabalhar.

A naturalidade de um projectista é um dos elementos que atribuiu identidade a um projecto mas este aspecto não é suficiente para vincular um artefacto à identidade local de um território. Actuar segundo uma identidade local significa participar nessa comunidade, pesquisando e investigando os costumes, os rituais, os mitos, os materiais, as práticas e os saberes afectos a esse território, manuseando todo este manancial no projecto, dando lugar a novas materializações identitárias.

A oportunidade de actuar no seio de uma identidade local implica o envolvimento do projectista nessa comunidade, desenvolvendo um processo de actuação que valoriza os elementos identitários e as práticas locais, disponibilizando metodologias de projecto adequadas às realidades do lugar.

O projectar no seio de uma identidade local pressupõe, como já se referiu, um exercício envolvido num colectivo na pesquisa de elementos tangíveis e intangíveis que suportam o desenvolvimento do projecto, fazendo uso de uma metodologia com base em métodos de campo e de representação, os quais mapeiam as manifestações arquitectónicas, pictóricas, escultóricas, artesanais, arqueológicas, gastronómicas e as características naturais, bem como os valores da poesia, da música, dos costumes, das tradições e dos cultos.

Esta aproximação permite, por um lado, eleger as especificidades de um território através dos elementos caracterizadores dos seus patrimónios histórico e cultural e, por outro, conciliar num mesmo suporte representativo os diferentes elementos que participam na construção de uma identidade local.

A gestão destes recursos por parte do designer consolida programas de projecto, sustentados em escolhas e hierarquias, disponibilizando soluções inovadoras no contexto da identidade local.

As práticas inovadoras que os projectos estabelecem com as características identitárias de um lugar manifestam-se em diferentes contextos e em múltiplas soluções materiais, das quais se destaca, entre outras: - a concepção de objectos que apoiam uma actividade particular desse lugar, aligeirando e sistematizando as tarefas a executar; - artefactos que valorizam um produto ou um material da região, apresentado novas propostas de uso e aplicação que evidenciam a sua qualidade e desempenho; - concepções que recuperaram uma actividade esquecida no passado, projectando-a através de um novo enquadramento para o presente e futuro; - reinterpretações e reconfigurações de reportórios visuais e materiais que dão origem a sistemas de objectos que sustentam novas práticas; - hábitos, mitos e lendas locais que são resgatadas através de projectos para a contemporaneidade e a utilização de técnicas e modos de fazer ancestrais aplicadas na construção de novos artefactos.

Estas são apenas algumas das propostas que resultam da aproximação do design à identidade local. As solicitações que fomentam estes projectos partem de uma comunidade e dirigem-se para essa mesma comunidade não inibindo a sua difusão a contextos mais amplos que transpõem o próprio território, região ou país, não perdendo, com esta transferência de lugar, a natureza da sua identidade.

Neste quadro local, o design participa na concepção de objectos que fomentam as oportunidades disponibilizadas pelo território, concebendo através da sua mediação uma proximidade cultural, permitindo aos artefactos integrarem e renovarem novas identidades. 


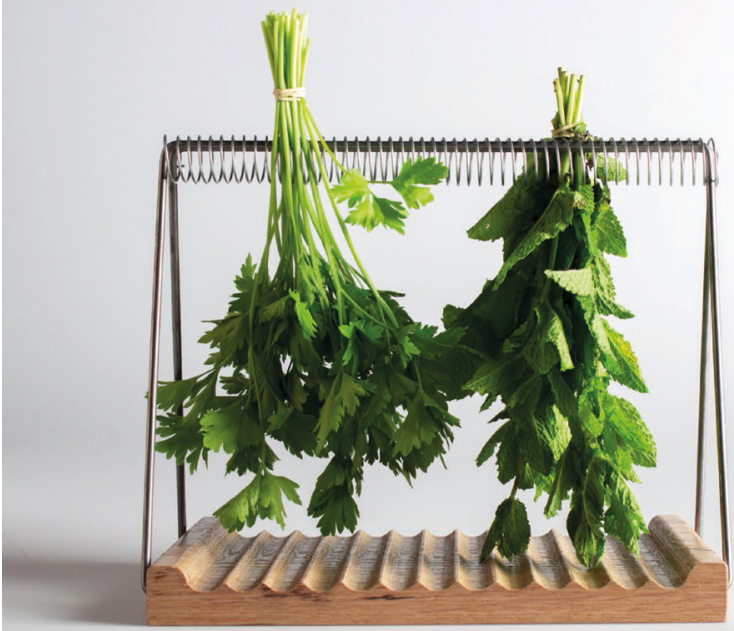

Fig. 6. Herbdryer

Design: Joana Ramos

Designesart - Novos Rituais Novas Práticas Locais

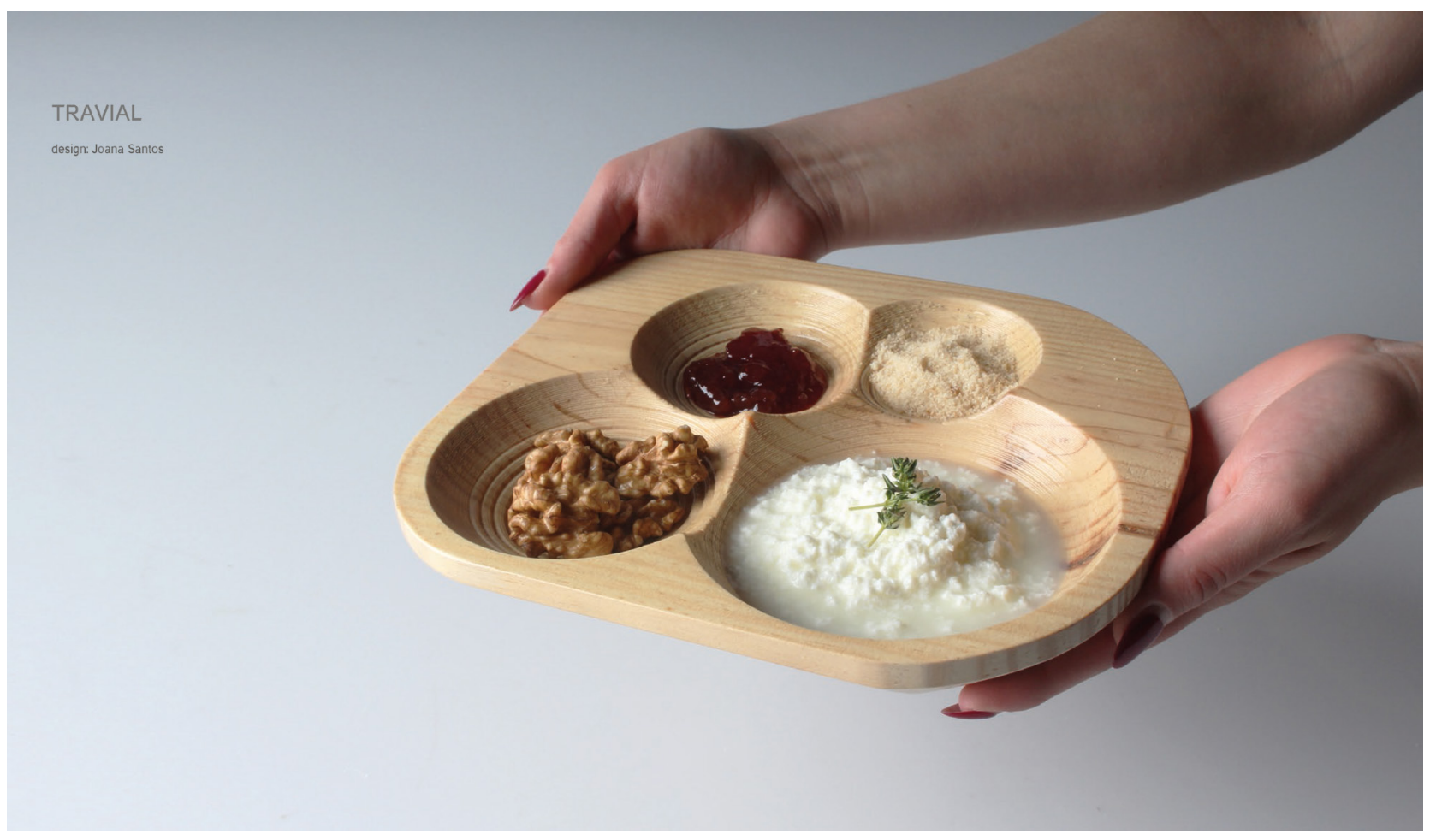

Fig. 7. Travial

Design: Joana Santos Designesart - Novos Rituais Novas Práticas Locais 
Outra das dimensões que os artefactos adquirem no contexto do projecto para uma identidade local é a longevidade. Esta qualidade está intimamente relacionada com o facto de os objectos vincularem atributos dos lugares facilmente reconhecidos por quem com eles interage, fazendo com que esta singularidade os distinga dos demais e os faça perdurar no tempo através dos valores que transmitem. Estes valores que podem ser materiais, ambientais, sociais, económicos, culturais, simbólicos ou funcionais apelam à sua preservação, reservando em si uma ligação com o lugar.

A longevidade dos objectos é um valor central nos nossos dias aumentando a sua vida útil e prevendo a sua reutilização não os sujeitando, assim, à constante reciclagem que coloca cada vez mais questões em termos ambientais.

A capacidade de preservar memórias, constitui também um dos aspectos centrais dos objectos de uma identidade local, quer através dos materiais naturais que os configuram, instituindo-se ligações a um local, quer pelas práticas que suportam, remetendo, muitas das vezes, para uma localização precisa.

Os objectos são assim uns dos referentes que retêm os valores da memória de uma identidade através dos elementos visuais, morfológicos e de uso que vinculam. Estes valores suportam em muitos casos a concepção de novos artefactos que partem dos conceitos iniciais e os adequam às circunstâncias de outros tempos.

A transmissão de conceitos entre objectos não é directa, obedecendo a uma dinâmica que envolve o local estabelecendo-se novos propósitos que são distintos em relação aos iniciais. Este processo de transferência de valores cria um ciclo que permite difundir os elementos perpetuando-os no tempo, traçando um percurso material de memorias de uma identidade.

É assim possível criar um trajecto temporal através dos artefactos afectos a uma identidade local, identificando a sua época e as circunstâncias que participam na sua concepção.

A memória é também o veículo da tradição de um lugar. É através dos elementos identitários preservadores da memória que se transmitem as tradições. Estas manifestações culturais são recuperadas e reformuladas por novos artefactos que renovam a identidade de um território.

São os valores da memória, da tradição e das qualidades dos materiais naturais, intrínsecos aos objectos de uma identidade local, que os torna vivenciados e por esta razão mais próximos do Homem.

Estas suas características humaniza-os e disponibiliza significados, favorecendo a sua harmoniosa integração no quotidiano.

A identidade é na sua génese imaterial, remetendo-nos para um espaço virtual onde o imaginário colectivo de uma dada comunidade habita e onde a idealização e a criatividade podem ser os reais axiomas da sua materialização, tal como constata Gui Bonsiepe: «A identidade não depende tanto do que cada um é ou tem, mas do que vive no imaginário do outro, ou seja, as identidades pertencem ao l'imaginaire, são artefactos de comunicação.» (Bonsiepe, 2012, p. 71).

A partir destas primeiras décadas do século XXI, assistimos a uma nova alteração da identidade no design. Assente num conjunto de transformações, das quais se destaca a reformulação da indústria que começa a abandonar, pela primeira vez, o seu arquétipo consolidado ao longo da Revolução Industrial e implementa um modelo mais flexível onde no mesmo espaço virtual coabitam técnicas e tecnologias que congregam práticas de produção industriais e artesanais. 


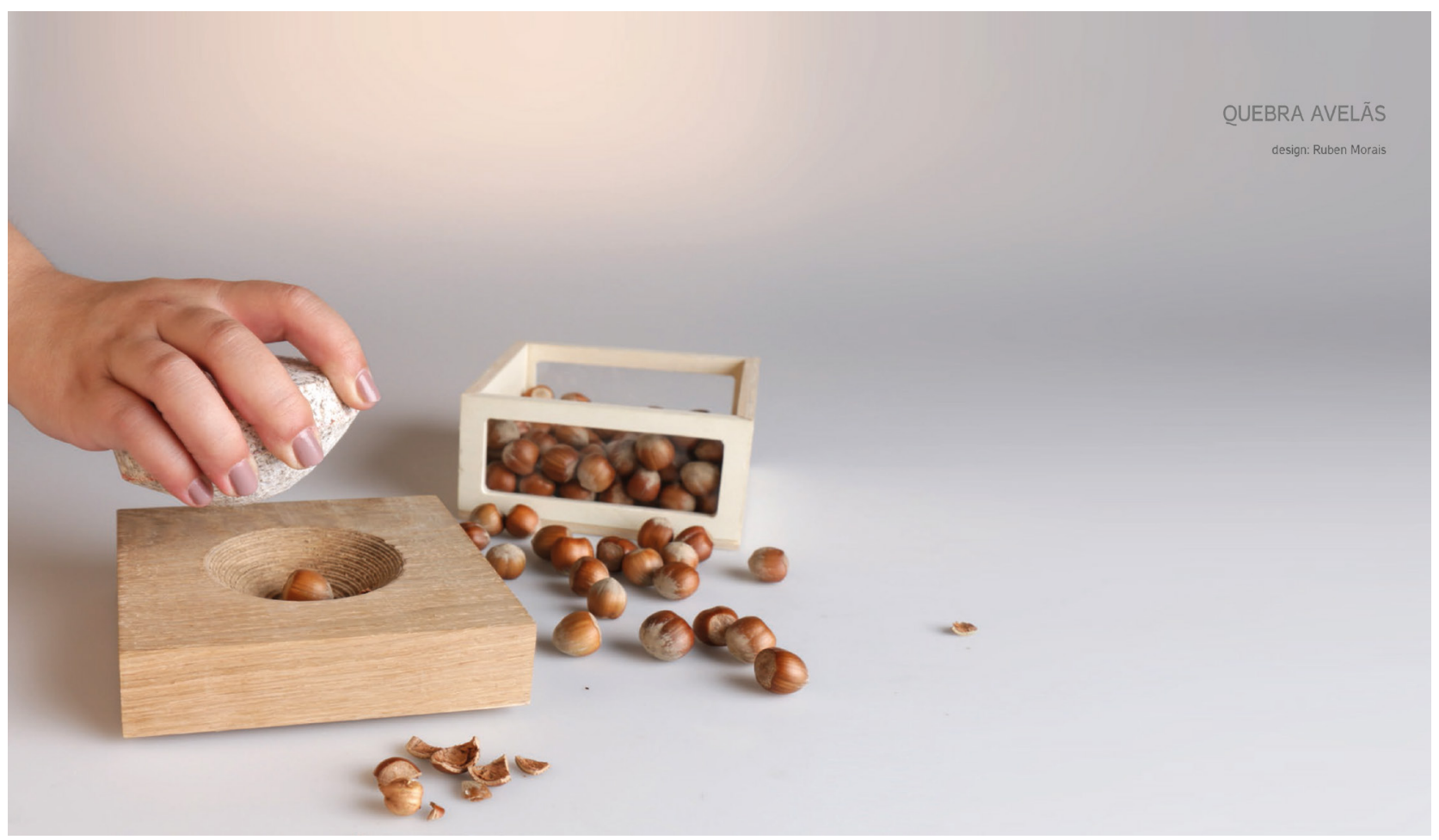

Fig. 8. Quebra Avelãs Design: Ruben Morais. Fotografia do autor Designesart - Novos Rituais Novas Práticas Locais
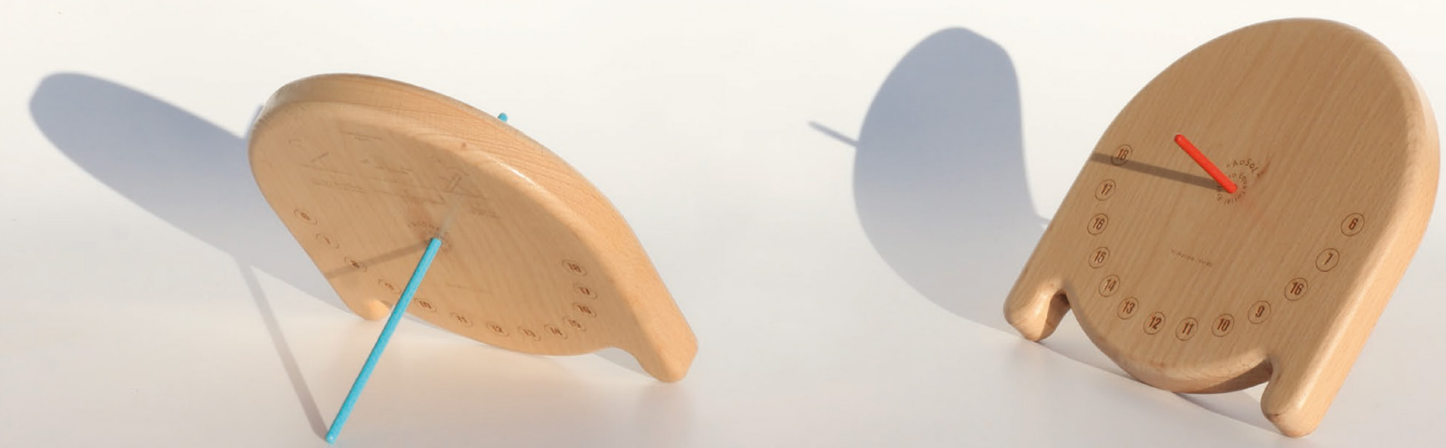

Fig. 9. Ao Sol 


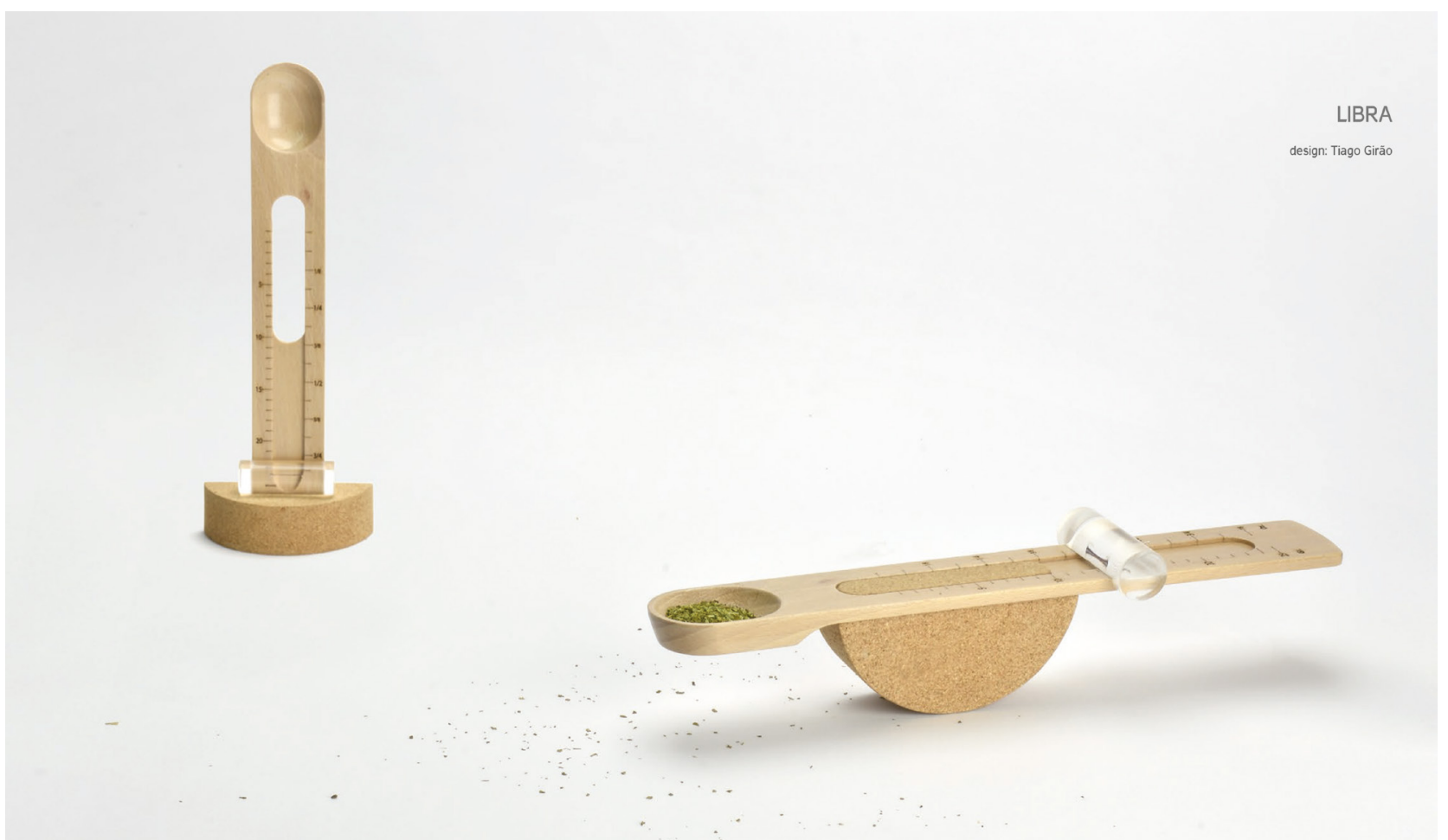

Fig. 10. Libra

Este modelo que aproxima estas duas práticas, no que diz respeito às artesanais, não se refere apenas a um âmbito mais tradicional, actualmente os novos artesãos manipulam máquinas informatizadas que permitem operações de grande complexidade técnica, introduzindo qualidade e inovação na produção.

O novo artesanato está alicerçado em redes de partilha de conhecimento, virtuais e presenciais, possibilitando aos seus interlocutores acesso a uma multiplicidade de informação e aquisição de competências técnicas. Estas estruturas atribuem grande flexibilidade às comunidades dos novos artesãos, explorando uma interessante dimensão social vital para esta actividade.

O valor técnico que desde sempre esteve associado ao fazer manual, delineador da materialidade dos artefactos, é actualmente incrementado de ferramentas digitais que atribuem ao resultado final maior qualidade e diversidade, não perdendo, pela utilização destas tecnologias, a sua importante raiz cultural, na qual a identidade local é um dos seus garantes.

A capacidade técnica de "aprender fazendo", ou seja de chegar à materialização de um processo através da experimentação, está actualmente potenciada por um novo ferramental virtual e material que possibilita chegar a resultados que eram inatingíveis num passado recente, quer no que diz respeito à dimensão dos recursos e do tempo para atingir um determinado fim, quer pela qualidade do resultado final, fazendo dos modelos experimentais produtos acabados, permitindo ainda a sua reprodutibilidade.

Neste novo quadro produtivo os processos sofrem alterações democratizando-se os meios, dando lugar a princípios que permitem ao designer gerir todo o processo de produção do artefacto, quer seja na dimensão que diz respeito à totalidade do projecto, quer seja na prática da gestão, ou ainda na sua relação directa com 
o utilizador, aplicando metodologias que vão desde a auto-produção ao design participativo. Sobre estes aspectos Federica Dal Falco observa: «É uma investigação de projecto culta e ética, que se situa no panorama internacional com uma identidade forte e própria, coerente com a cultura da sustentabilidade em relação à qual todos os designers hoje têm o dever de enfrentar.» (Dal Falco, 2014, p. 20).

O projecto e a produção de artefactos envolvidos no âmbito da valorização local, deve potenciar assim quer os recursos materiais, quer os meios imateriais como os saberes, as práticas e as características locais.

Este valioso património cultural constitui o suporte do projecto, com o qual o designer interage, promovendo uma solução adequada ao enquadramento em que intervém.

Estabelece-se assim uma relação directa entre objectos e território, disponibilizando, através do design, parâmetros de adequação, criatividade, qualidade e produção que, aproximam a inovação dos valores da tradição e da memória local.

Neste contexto o design constitui um importante motor do desenvolvimento local, envolvendo os diferentes intervenientes da comunidade e fomentando, através do projecto, as estruturas culturais e produtivas do território.

Para além desta raiz identitária os meios de produção e divulgação são fundamentais para o sucesso de todo o processo. As novas tecnologias de fabricação digital promovem, neste contexto, uma qualidade acrescida com redução de meios, permitindo colocar o produto do projecto num patamar global valorizando a região e disseminando a sua identidade local.

A divulgação dos produtos desta identidade é outro dos factores preponderantes, encontrando-se facilitada nos nossos dias através das plataformas disponibilizadas pela internet, preponderantes para a difusão global dos produtos.

Este novo paradigma de projecto e produção veio alterar a relação do design com a identidade.

Em primeiro lugar, aproximou o design e os designers, deixando de ser o modelo económico e industrial a definir uma suposta fasquia para o que é design e o que não é design. A importância da disciplina começou a centrar-se na sua prática, ou seja no projecto, independente deste se localizar geograficamente num país desenvolvido ou não. E em segundo lugar, as diferenças culturais deixaram de ser diferenças e constituíramse como atributos de uma materialidade que do local passou ao global. Como afirma Bonsiepe: «identidade e globalização ocupam uma posição central no actual discurso do design.» (Bonsiepe, 2012, p. 63).

O design passou assim a incrementar os valores da identidade local como traço distintivo e manifesto de uma cultura, bem como veículo de comunicação dessa mesma cultura, propiciando experiências de variadíssimas naturezas que, partindo das localizações mais particulares e mais distantes, se tornam próximas através do design. 


\section{Bibliografia}

Bauman, Z. (2005). Identidade: Entrevista a Benedetto Vecchi. Rio de Janeiro, BR: Jorge Zahar Editor.

Bonsiepe, G. (2012). Diseño y Crisis. Valencia, ES: Campgràfic Editors.

Cunca, R. (Coord.). (2015). Designesart: Identidade local e design global, Castelo Branco, PT: IPCB.

Cunca, R. (Coord.). (2018). Designesart: Novos Rituais Novas Práticas Locais, Castelo Branco, PT: IPCB.

Cunca, R. (2006). Territórios Híbridos. Lisbon, PT: FBAUL.

Dal Falco, F. (2014). Os Objectos de Raul Cunca e a Cultura da Sustentabilidade. In A. Canelas \& R. Cunca (Coords.), Raul Cunca. O Design Plural - The Plural Design (pp. 19-21). Almada, PT: Casa da Cerca.

Micelli, S. (2015). Futuro Artigiano: L'Innovazione nelle Mani degli Italiani. Venica, IT: Mardilio Editori.

Micelli, S. (2016). Fare è Innovare. II Nuovo Lavoro Artigiano. Bologna, IT: II Mulino.

Sennett, R. (2012). L'Uomo Artigiano. Milan, IT: Feltrinellie.

\section{Índice das Figuras}

\section{Figura 1}

Carimbos de Castelo Branco

Design: Ana Alice Afonso

Fotografia da autora

Projecto de Identidade local: Designesart - Novos Rituais Novas Práticas Locais

Comissário Científico: Raul Cunca

\section{Figura 2}

R'olive

Design: Ana Catarina Reis

Fotografia da autora

Projecto de Identidade local: Designesart - Novos Rituais Novas Práticas Locais

Comissário Científico: Raul Cunca

\section{Figura 3}

Carrossel para Linhas de Costura

Design: Ana Lourenço

Fotografia da autora

Projecto de Identidade local: Designesart - Novos Rituais Novas Práticas Locais

Comissário Científico: Raul Cunca 


\section{Figura 4}

Dulcis Syringes

Design: Ana Simões

Fotografia da autora

Projecto de Identidade local desenvolvido na Beira Baixa, Portugal:

Designesart - Novos Rituais Novas Práticas Locais

Comissário Científico: Raul Cunca

\section{Figura 5}

Jardim Vertical

Design: Carla Lourenço

Fotografia da autora

Projecto de Identidade local desenvolvido na Beira Baixa, Portugal:

Designesart - Novos Rituais Novas Práticas Locais

Comissário Científico: Raul Cunca

\section{Figura 6}

Herbdryer

Design: Joana Ramos

Fotografia da autora

Projecto de Identidade local desenvolvido na Beira Baixa, Portugal:

Designesart - Novos Rituais Novas Práticas Locais

Comissário Científico: Raul Cunca

\section{Figura 7}

Travial

Design: Joana Santos

Fotografia da autora

Projecto de Identidade local desenvolvido na Beira Baixa, Portugal:

Designesart - Novos Rituais Novas Práticas Locais

Comissário Científico: Raul Cunca 
Figura 8

Quebra Avelãs

Design: Ruben Morais

Fotografia do autor

Projecto de Identidade local desenvolvido na Beira Baixa, Portugal:

Designesart - Novos Rituais Novas Práticas Locais

Comissário Científico: Raul Cunca

\section{Figura 9}

Ao Sol

Design: Tiago Milheiro Silva

Fotografia do autor

Projecto de Identidade local desenvolvido na Beira Baixa, Portugal:

Designesart - Novos Rituais Novas Práticas Locais

Comissário Científico: Raul Cunca

\section{Fotografia 10}

Libra

Design: Tiago Girão

Fotografia do autor

Projecto de Identidade local desenvolvido na Beira Baixa, Portugal:

Designesart - Novos Rituais Novas Práticas Locais

Comissário Científico: Raul Cunca 